\title{
EUTANÁSIA: DIREITO A UMA MORTE DIGNA
}

Mylena Alves Tavares, Tatiane Neves Benites.

Universidade do Oeste Paulista. UNOESTE, curso de Direito, Presidente Prudente, SP. E-mail: Mylenaat@gmal.com

\section{RESUMO}

A proposta apresentada neste projeto vai ao encontro do respeito à vida humana e as diretrizes que ela abrange, uma vez que não basta estar vivo sem se sentir efetivamente vivo. $O$ "direito a uma morte digna" pode ser extraído do próprio principio da dignidade da pessoa humana, pois eventual prolongamento artificial da vida pode atentar contra sua dignidade, enquanto sujeito de direito, nos termos constitucionais. Busca-se despertar a atenção para a importância da utilização destas informações para melhorar procedimentos e produzir novos saberes, na área da saúde e prisma acadêmico, com vistas a serem aplicados no interesse da sociedade. Neste enfoque, este trabalho irá visar pautar as consequências dos efeitos da aplicação legalizada da eutanásia, abordando questões biológicas, objetivas, e claro as divergências subjetivas do tema, como no âmbito da filosofia, moral, religião, entre outros desmembramentos, uma vez, que trata-se de um assunto que transcende uma única visão padronizada.

Palavra-Chave: Eutanásia, Dignidade da Pessoa Humana, morte digna, direito constitucional, liberdade de escolha.

\section{EUTANASIA: RIGHT TO DIGNATIAL DEATH}

\begin{abstract}
The proposal presented in this project meets the respect of human life and the guidelines that it covers, since it is not enough to be alive without feeling really alive. The "right to a dignified death" can be extracted from the very principle of the dignity of the human person, since artificial prolongation of life may violate its dignity, as a subject of law, in constitutional terms. Attention is drawn to the importance of using this information to improve procedures and produce new knowledge in the health area and academic prism, with a view to being applied in the interest of society. In this approach, this work will aim at guiding the consequences of the legalized application of euthanasia, addressing biological, objective, and clear subjective differences of the theme, such as in philosophy, morality, religion, among other dismemberments, since it is a matter that transcends a single standardized view.
\end{abstract}

Keyword: Euthanasia, Dignity of the Human Person, worthy death, constitutional law, freedom of choice. 


\section{INTRODUÇÃO}

Enfrentar a morte, lidar com alguém que está morrendo, assentir com o fato da nossa própria mortalidade. Essas são algumas das preocupações que acompanham o ser humano desde os tempos remotos. A dificuldade de encarar a finitude humana, associada com os avanços tecnológicos no âmbito da ciência e saúde, possibilitam inúmeras cirurgias, procedimentos e tratamentos, o que acarreta na busca pelo uso de intervenções terapêuticas, e é neste ponto que as pessoas começam a evitar ou adiar a morte ao máximo, a maior inimiga dos homens. (MÖLLER, 2007).

Com esses mecanismos a sociedade acredita estar conquistando vitórias, mas tão só acarretam um final de vida muitas vezes excessivamente prolongado e sofrido. Observa-se, pois, uma fronteira entre a vida e a morte, desapropriando o moribundo da sua própria morte, ou seja, da sua liberdade em escolher por um óbito com dignidade. (GODINHO, 2016).

Reforça ainda que a morte sempre foi considerada um tabu, mas felizmente os progressos da medicina e da farmácia permitiram estender a vida, muito além do que acontecia nas gerações anteriores, pois há um prognóstico da doença e a delimitação de quais os melhores tratamentos. Todavia, a humanidade também evoluiu em seu pensamento. A sociedade vem caminhando no sentido de proteger o direito de cada indivíduo de se "reapropriar da própria morte", o que justifica o aumento de discussões no âmbito jurídico sobre a prática da eutanásia, e o respeito à vontade do paciente.

Neste diapasão, objetiva, o presente projeto, tomar a discussão da eutanásia, analisando os efeitos e a finalidade da mesma frente ao direito a vida, extraindo a normatização ou adequação constitucional sobre o tema, bem como identificar como o principio da dignidade da pessoa e do direito a vida podem ser analisados na Constituição Federal e se inter-relacionam.

\section{METODOLOGIA}

O presente trabalho empregou pesquisas à legislação nacional, jurisprudências, levantamento bibliográfico de obras que retratam o tema, artigos e revistas relevantes na matéria objeto de estudo. Utilizando o método dedutivo para assomar o raciocínio lógico, bem como a dedução, observando minunciosamente os fatos e argumentos que a problemática traz, a fim de cumprir o objetivo proposto.

\section{RESULTADOS}

O desígnio desse projeto fora a apresentação da discussão conceitual sobre a eutanásia, bem como observar sua aplicação frente ao princípio da dignidade da pessoa humana, denotando sua prática sob o diapasão social, cultural, filosófico, religioso, científico e para o prisma acadêmico, trazendo a baia os efeitos da sua aplicação legalizada (prós e contras).

\section{EUTANÁSIA: NOÇÕES GERAIS}

Embora a prática da eutanásia seja muito antiga, talvez tanto quanto a própria espécie humana, vindo de longe a discussão a respeito, o tema vem despertando um interesse cada vez maior, manifestado por especialistas de diversas áreas e pela sociedade em geral, especialmente em virtude do aumento da expectativa de vida da população e da possibilidade de prolongamento dos sinais vitais quase indefinidamente. (VIEIRA, 2009, p.21).

A eutanásia é uma expressão ampla que pode envolver tanto os direitos pessoais do cidadão numa visão voltada ao ordenamento jurídico e suas normas de ordem social, como debates sobre questões éticas, morais, religiosas e filosóficas. Na medicina ela é encarada como um ato de proporcionar a morte sem sofrimento a um indivíduo extremamente doente, culminado por afecção incurável, que geralmente produz dores intoleráveis. 
Já no âmbito jurídico, é o direito de matar ou morrer pelas razões explicitadas acima, bem como, em consonância com a dignidade da pessoa humana, levando-se em consideração todos os aspectos que regem uma vida.

De acordo com Letícia Ludwig Möller (2008, p. 18):

A problemática referente ao fim da vida, à definição de rumos de tratamento de pacientes terminais e ao modo de morrer, envolve dilemas éticos e impasses de natureza jurídica, fazendo com que os profissionais da saúde - não somente estes, mas também estudiosos de áreas diversas e mesmo o público leigo - reflitam criticamente acerca da conduta ética e juridicamente mais adequada diante da terminalidade de uma vida humana.

A autora expõe em poucas palavras algumas razões pelas quais este tema é tratado com tanta delicadeza e por várias vertentes. O homem busca através de a sua racionalidade pontuar os critérios positivos e negativos do ato de encerrar a vida por livre escolha do paciente. Logo, independentemente da forma de se praticar a eutanásia, seja legalizada ou não, isto é considerado um assunto controverso, existindo sempre prós e contras, bem como, o surgimento de teorias eventualmente mutáveis com o tempo e a evolução da sociedade, tendo sempre em conta o valor de uma vida humana.

\section{CONSTITUIÇÃO FEDERAL: O DIREITO A VIDA E A LIBERDADE DE ESCOLHA}

Os direitos da personalidade que afloram da Constituição Federal proporcionam inúmeras hipóteses de aproveitamento, num sentido positivo, ao exercício dos direitos inerentes à pessoa humana, mas não permitem a sua própria eliminação.

O art. 5o da Constituição da República, logo em seu caput, consagra o princípio da inviolabilidade da vida humana. Antes mesmo de enumerar outros direitos fundamentais, o texto constitucional conferiu adequada primazia ao direito à vida, atribuindo-lhe, em acréscimo, a qualidade de inviolável.

Isto, contudo, não se mostra suficiente para resolver os dilemas que se colocam ao tema, uma vez que seguindo o direito à vida, a Carta Magna também reserva os direitos fundamentais de uma vida digna, com a saúde, educação, lazer, entre outros. Ora, se o cidadão não se vê mais possibilitado em exercer seus direitos, em manter-se com a dignidade que merece e espera, sem aproveitar dos benefícios que a vida Ihe proporcionaria em um quadro de saúde melhor ao qual se encontra, com a possibilidade de explorá-la, participando de coisas que tem afinidade, como esporte e demais recriações, como mantê-lo apenas "existindo sem viver"? E mais, contra sua vontade.

\section{UM OLHAR HUMANITÁRIO AO ORDANAMENTO JURÍDICO BRASILEIRO}

Uma grande questão colocada em pauta é se uma pessoa teria o direito de pedir para morrer e abreviar seu sofrimento diante de uma doença incurável. Para muitos especialistas, sim, a prática da eutanásia deveria ser a expressão da vontade do sujeito, e não uma brecha para a interferência estatal, e até mesmo para o fortalecimento de ideologias criadas por pessoas que não estão encarrando a situação naquele momento, ou seja, dissemelhante do próprio paciente, este que pode medir a extensão de sua dor física e mental.

Temos tecnologia capaz de manter um paciente vivo por um lapso temporal incerto, pelo amor que a família do indivíduo nutre por ele, muitas vezes, ao invés de ajudá-lo nesta difícil situação e atender seu desejo, bem como, compelidos pela norma legal, acabam praticando algo muito ruim, que seja, a manutenção do sofrimento do indivíduo por dias, semanas e até meses.

A morte é inevitável, porém passa a ser adiável. Todavia, quem tem autonomia para decidir a intensidade que uma pessoa deverá sofrer antes de morrer?

É incontestável o entendimento de que o paciente possui autonomia para decidir sobre seu corpo, sob a luz dos direitos da personalidade, a autonomia de vontade e a dignidade da pessoa 
humana, uma vez que o prolongamento artificial da vida lhe retirará esse direito fundamental, estando ele de mãos atadas, sem voz, e suportando todo o tormento em estar vivo. (SALDANHA, 2017).

Diante disto, se a eutanásia fosse um assunto ponderado para obter a sua legalização, muitos suicídios poderiam ser evitados, as dores não mais prolongadas e obviamente, o paciente teria acompanhamento psicológico para determinar seu quadro, se este é irreversível e plausível a eutanásia, ou se há chances de reversão. Seja como for, esse debate ainda está longe de ser concluído.

Se legalizada, não seria uma prática injustificada e desenfreada. Por se tratar de algo delicado, sua aplicação, como em outros países que já legalizaram, será pautada em alguns passos, ou quesitos, analisando cada caso em sua individualidade.

De todo modo, estas ponderações e critérios que assomam os dias atuais, não são suficientes para oferecer solução à ampla gama de delicadas possibilidades que o tema acarreta, mas abrem espaço para a investigação de resoluções.

\section{CONCLUSÃO}

Em nenhum outro momento histórico se contou com um acervo de informações sobre a Eutanásia como existe hoje, o questionamento e pesquisa aumentaram consideravelmente com o passar do tempo. Este trabalho colabora para a informação e sua difusão, quebrando as barreiras que impossibilitam os avanços da sociedade, favorecendo a construção de soluções e a exploração acadêmica, colaborando para a ampliação da investigação e conhecimento.

O desenvolvimento científico permitiu uma melhora importante e sem precedentes na qualidade de vida, entretanto, ainda não se mostra suficiente, uma vez que o quesito qualidade é colocado em dúvida, pois, mesmo aquele que vive na angustia de não poder morrer, privado de várias atividades e do gozo de seus direitos (como o lazer, por exemplo), ainda tem uma qualidade de vida proeminente?

Complementamos todo o exposto com o pensamento do filósofo dinamarquês Søren Aabye Kierkegaard:

Quando a morte é o maior perigo, se espera na vida; mas quando se encontra um perigo ainda maior, se espera na morte. Entretanto quando este perigo é tão grande que a morte se torna a esperança, o desespero é a não esperança de não poder nem mesmo morrer.

Destarte, tem-se a morte como um lampejo de esperança àquele que se encontra limitado a viver.

\section{REFERÊNCIAS}

GODINHO, Adriano Marteleto. Eutanásia, ortotanásia e diretivas antecipadas de vontade: o sentido de viver e morrer com dignidade. 1. ed. Curitiba: Juruá Editora, 2016. Disponível em: <https://www.jurua.com.br/shop_item.asp?id=25089>. Acesso em: 25 mar. 2018.

MÖLLER, Letícia Ludwig. Direito à Morte com Dignidade e Autonomia. 1. ed. Curitiba: Juruá Editora, 2007. Disponível em: <https://www.jurua.com.br/bv/conteudo.asp?id=20187\&pag=5>. Acesso em 25 mar. 2018.

NEUMAM, Camila. Como funciona a eutanásia no Brasil?. Folha de São Paulo, São Paulo, 06 out. 2016. Disponível em: <https://noticias.uol.com.br/saude/ultimasnoticias/redacao/2016/10/06/por-que-o-brasil-nao-aprova-a-eutanasia-religiao-e-politica-nao-seacertam.htm>. Acesso em: 25 mar. 2018. 
PRESSE, France. Cientista australiano de 104 anos viajará à Suíça para morrer. Folha de São Paulo, São Paulo, 30 abr. 2018. Disponível em: <https://g1.globo.com/bemestar/noticia/cientistaaustraliano-de-104-anos-viajara-a-suica-para-morrer.ghtml>. Acesso em: 01 maio. 2018.

SALDANHA, Rodrigo Róger. Testamento vital: aspectos controversos e a autonomia do enfermo. 1. ed. Curitiba: Juruá Editora, 2017. Disponível em: <https://www.jurua.com.br/bv/conteudo.asp?id=26232\&pag=2>. Acesso em 25 mar. 2018.

URBAN, Cícero de Andrade. A questão da eutanásia no Brasil. Folha do Paraná, Curitiba, 8 fev. 2009. Disponível em:

<http://www.gazetadopovo.com.br/opiniao/artigos/a-questao-da-eutanasia-no-brasilbeylcrsz9pieiu6teug66164u>. Acesso em: 18 abr. 2018.

VIEIRA, Mônica Silveira. Eutanásia: Humanizando a visão jurídica. 1. ed. Curitiba Editora, 2009. Disponível em: <https://www.jurua.com.br/shop_item.asp?id=21333>. Acesso em 25 mar. 2018. 